\title{
Pathology of Snake bite in stray Dog
}

\author{
Kamdi B. P. ${ }^{1}$, Shrikhande N. G. ${ }^{2}$, Pande R., R. Padole, P. M. Sonkusale and A. \\ G. Bhandarkar \\ Department of Veterinary Pathology, Nagpur veterinary college, Nagpur,India.
}

\begin{abstract}
In the present study pathological investigations of two year old stray dog carcass were carried out. This had history of swelling at right forelimb with snake bite marks, salivation, restlessness followed by death. Gross and histopathological lesions shown by affected dog were suggestive of snake bite of Viperidae family, as the lesions were hemotoxic as evidenced in heart, lungs, kidney and trachea.
\end{abstract}

Keywords: Cyanosis, Necropsy, Venom

\section{Introduction}

Cases of snake poisoning are most commonly encountered in the veterinary practice. Venomous snake bites are responsible for more than one lakh animal death in the world annually (Banga et al. 2009). In the Indian subcontinent there are nearly 200 species of snake among them the common venomous snakes encountered are the Indian Cobra (Naja naja), Russell's viper (Daboia russelli) and the Common Krait (Bungarus caeruleus) (Thangapandiyan et al. 2013, Yogiraj et al. 2013). In animals, most of the snake bite cases remain unnoticed and responsible for their death. Therefore present communication is planned to study pathological features of snake bite in stray dog.

\section{Material And Methods:}

A two year old female Labrador dog was presented for necropsy examination with the history of development of swelling at right forelimb, salivation, restlessness and death. Systemic necropsy examinations were performed and various visceral organs like swollen muscle piece, kidney, heart, liver, spleen and lung were collected in $10 \%$ buffered formal saline solution. The tissue samples after making $5 \mu$ thick sections were processed for routine Hematoxylin and Eosin staining protocol as per standard protocol of Luna (1968).

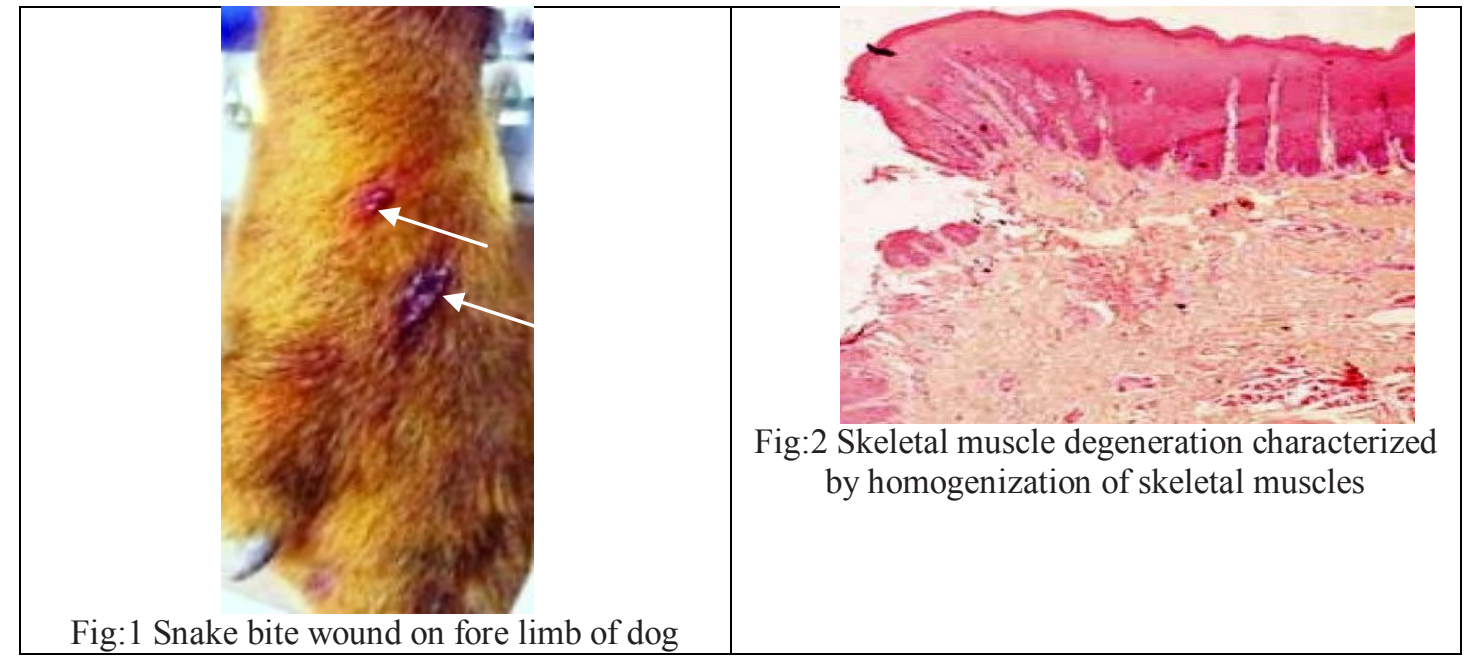

\section{Result And Discussion:}

On post-mortem the carcass revealed severe cyanotic conjunctival mucous membrane. There was punctured wound with oedema and haemorrhage on the right forelimb. The subcutaneous muscles showed extensive edema and haemorrhage at the site of bite. Lungs showed congestion and haemorrhages with mild oedema. Liver and kidneys were enlarged and congested. Spleen showed diffuse haemorrhages and brain revealed mild congestion.

Histopathological examination revealed, neutrophilic infiltration, oedema, necrosis and degeneration in the skin and muscles at sight of the bite 
Heart revealed myocardial congestion. Lung parenchyma and alveoli were haemorrhagic and congested. Liver revealed area of necrosis and fatty degeneration. Kidney revealed tubular epithelial cell necrosis with blocking of tubular lumen.

Generally, snake bite in animals occur during playing in the garden, grazing or during hunting. Most of the cases of snake bite have been reported in the dogs and horses. In dogs, frequently affected sites by snake bite are head, muzzle, tongue, lips $(65 \%)$, neck (13\%), thorax and abdomen $(7 \%)$, hind limbs $(5 \%)$ (Willey and Shaer, 2005).

In the present case, haemorrhege and swelling at the site of bite with clinical signs of salivation, pain, cyanosis and abnormal behaviour were noticed. Snake bite resulted into multi-organ failure due to fall in effective blood pressure since venom is responsible for the increase in permeability of capillary membranes (Nuri Mamak, 2009, Peterson, 2006), as observed in the present case.

Interstitial oedema and cellular infiltration, necrosis of tubular epithelium cell in kidney were observed in haemotoxic snake bite (Visith Sitprijs, 2006). The pathological findings reported in case of viper bites include myonecrosis, hemolysis, nephrotoxicity, myocardial necrosis, increased vascular permeability, subcutaneous edema, shock and death (Vani Prasad and Koley, 2009) which was similar to the findings of present study.

Depending upon history, gross pathology and histopathology, present case was diagnosed as snake bite which was belongs to Viperidae family.

\section{References}

[1] H. S. Banga, R. S. Brar, S. G. Chavhan, H. S. Sandhu and A. M. Kammon, Pathology of snake bite in cow. Toxicol Int, 16, 2009, 6971 .

[2] M.Thangapandiyan, R. Mohanpriya, B. Murli Manohar. and C. Balachandran, Pathology of Snake envenomation in a dog, Indian Vet. J., 90 (5), 2013, 119-120.

[3] V. Yogiraj, R. Chaithanya, B. Jatti Vijayakumar, N. Patil Anand and C. Bharat, A study of post mortem histopathological findings in snake bite poisoning ,13 (1), 2013, 203-208.

[4] L.G. Luna, (Manual of Histochemical Staining Methods of Armed Forces Institute of Pathology, 3rd edn. Mc Graw Hill Book Co. New York, 1968 )

[5] J. R. Willey and M. Schaer, J Am Anim Hosp Assoc., 41, 2005, 22-23.

[6] Nuri Mamak IsmaliAytekin, J Anim Vet Adv., 8, 2009, 2392-2394.

[7] M. Peterson, Clin. Technol. Small Animal. Pract., 21, 2006, 183-186.

[8] Visith Sitprija, Nephrology, 11, 2006, 442-448.

[9] V. Vani Prasad, and K. M. Koley, (Synopsis of veterinary Phormacology and Toxicology, $1^{\text {st }}$ edn. Vahini Publications, 2006) $324-$ 325. 